\title{
Valores de Digestibilidade de Alimentos Volumosos para Eqüinos ${ }^{1}$
Danilo Mariano Figueiredo², Kleber Villela Araújo ${ }^{3}$, José Augusto de Freitas Lima ${ }^{4}$, Elias Tadeu Fialho ${ }^{4}$, Eliane Sayuri Miyagi ${ }^{5}$

\begin{abstract}
RESUMO - Quatro ensaios de metabolismo foram realizados para obter informações sobre os valores de digestibilidade dos nutrientes na alimentação de eqüinos. Cavalos castrados, sem raça definida, com idade média de seis anos de idade foram usados. Nos experimentos foram testados: (1) cana-de-açúcar, (2) combinação de 59,0\% de cana-de-açúcar e 41,0\% de milho grão inteiro, (3) capim-elefante e (4) cana-de-açúcar com $1,5 \%$ de uréia. O consumo médio de MS foi de 0,$89 ; 1,11 ; 2,02 ;$ e 1,03\% PV para cana-de-açúcar, cana-de-açúcar mais milho grão inteiro, capim-elefante e cana-de-açúcar mais uréia, respectivamente. Os valores de energia digestível para cana-de-açúcar, cana-de-açúcar mais milho grão inteiro, cana-de-açúcar mais uréia e capim-elefante foram 2361, 3382, 2060 e $1182 \mathrm{kcal} / \mathrm{kg} \mathrm{MS}$, respectivamente. Cana-de-açúcar e canade-açúcar mais milho grão inteiro são boas fontes alternativas de alimentos para os eqüinos. O capim-elefante e a adição de 1,5\% de uréia a canade-açúcar apresentaram menor potencial nutricional como volumoso na alimentação de cavalos adultos.
\end{abstract}

Palavras-chave: cavalo, digestibilidade, alimento

\section{Values of Digestibility of Forage Feeds for Equines}

\begin{abstract}
Four metabolism assays were carried out to btain information on the nutrient digestibility of horses feeding. Geldings without definite breed, with average of six years of age, were used. In the experiments were tested: (1) sugar cane; (2) a combination of 59.0\% of sugar cane and $41.0 \%$ of whole corn grain; (3) elephant grass; (4) and sugar cane with $1.5 \%$ of urea. The average DM intake was .89, 1.11 , 2.02 and $1.03 \%$ LW for sugar cane, sugar cane plus whole corn grain, elephant grass, and sugar cane plus urea, respectively. The values of the digestible energy for sugar cane, sugar cane plus whole corn grain, sugar cane plus urea and elephant grass were 2361, 3382, 2060 and 1182 $\mathrm{kcal} / \mathrm{kg}$ DM, respectively. The sugar cane and sugar cane plus whole corn grain are good alternative sources of feed for equines. The elephant grass and addition of $1.5 \%$ of urea in sugar cane showed less potential as forage in the feeding of mature horses.
\end{abstract}

Key Words: horse, digestibility, feed

\section{Introdução}

Apesar de o Brasil possuir um dos maiores rebanhos de eqüinos do mundo, estes se encontram subutilizados na maioria das regiões brasileiras, em decorrência, principalmente, de alimentação inadequada. A escassez de forragens durante o período da seca contribui de forma acentuada para as carências nutricionais dos eqüinos. Por isso, a diversidade de forrageiras adaptadas às regiões tropicais e, normalmente, encontradas nas propriedades rurais brasileiras, como cana-de-açúcar e capim elefante, apresentam-se como alternativas alimentares de grande potencial durante os períodos de baixa disponibilidade de forragem.

A cana-de-açúcar como volumoso possui bom potencial produtivo caracterizado pelo seu aproveitamento em qualquer época do ano, pelo seu alto conteúdo de energia bruta e por se auto armazenar no campo. Porém, estudos envolvendo o uso deste volumoso na alimentação dos eqüinos no Brasil restringese a alguns trabalhos mais recentes (MACHADO, 1992; GARCIA, 1995), o que reforça a necessidade de mais pesquisas.

$\mathrm{Na}$ pesquisa realizada por MACHADO (1992) com potros 1/2 sangue Bretão Postier alimentados com diferentes proporções de cana-de-açúcar e capim elefante, a combinação de $45 \%$ de cana-de-açúcar e $55 \%$ de capim elefante proporcionou resultados satisfatórios, não influenciando os valores de digestibilidade. GARCIA (1995), objetivando avaliar o desempenho de potros com idade entre 15 a 20 meses de idade, alimentados com diferentes combinações de capim elefante com cana-de-açúcar $(0,10$, 20,30, 40 e 50\% de cana-de-açúcar), não observou 
efeito dos diferentes níveis de cana-de-açúcar sobre o ganho de peso dos animais e o consumo de matéria seca, matéria orgânica, fibra em detergente neutro e fibra em detergente ácido.

Utilizando a técnica do saco de náilon móvel para determinar a digestibilidade aparente dos nutrientes em eqüinos, ARAÚJO et al. (1996) encontraram para a cana-de-açúcar valores de digestibilidade aparente de 57,$46 ; 55,06 ; 54,37$; e $32,17 \%$, respectivamente, para matéria seca, proteína bruta, energia bruta e fibra em detergente neutro.

Entre as limitações do uso da cana-de-açúcar como volumoso, destaca-se o baixo teor de proteína bruta. Em ruminantes, o uso de cana-de-açúcar combinada com uréia objetivando corrigir o baixo teor de proteína, constitui uma prática adotada há vários anos, porém na alimentação de eqüinos são incipientes as citações na literatura. $\mathrm{O}$ uso de uréia na alimentação de eqüinos limita-se à adição em concentrados. Algumas pesquisas com pôneis adultos alimentados com dietas de baixo teor protéico suplementadas com uréia mostraram aumento na retenção de nitrogênio (SLADE et al., 1970; HINTZ e SCHRYVER, 1972), enquanto em outras não foi observado aumento (REITNOUR e TREECE, 1971; MARTIN et al., 1996).

O capim-elefante constitui um volumoso potencial na alimentação dos eqüinos, devido a sua adaptação ao corte e por possuir alto rendimento por área e bom valor nutricional. A utilização do capim-elefante foi avaliada em um experimento de desempenho com potras da raça Árabe e mestiças de Árabe, com idade média de 15 meses, por MANZANO et al. (1979). Esses autores alimentaram os animais com duas dietas: a primeira, composta de $40 \%$ de feno de capim rhodes e $60 \%$ de concentrado; e a segunda, composta de $40 \%$ de capim-elefante e $60 \%$ de concentrado. A dieta contendo o capim-elefante proporcionou maior ganho de peso em relação àquela contendo feno de capim rhodes, enquanto o consumo de matéria seca não foi influenciado pelas dietas testadas. No ano seguinte, MANZANO et al. (1980), trabalhando com as mesmas potras e dietas, não verificaram diferenças entre as duas dietas, para os coeficientes de digestibilidade aparente de matéria seca, proteína bruta, fibra bruta, extrativo não-nitrogenado e energia bruta. Esses autores concluíram ser possível a substituição do feno de capim rhodes pelo capimelefante, sem redução no desempenho dos animais.

Objetivou-se nesta pesquisa obter informações sobre o valor nutricional do capim-elefante, da canade-açúcar, da cana-de-açúcar com uréia e da cana- de-açúcar com milho grão inteiro na alimentação de eqüinos, estimando-se a digestibilidade aparente dos nutrientes nos respectivos alimentos.

\section{Material e Métodos}

Foram realizados quatro ensaios de metabolismo com eqüinos, no Departamento de Zootecnia da Universidade Federal de Lavras, no período de novembro de 1996 a fevereiro de 1997. Foram utilizadas gaiolas metabólicas para eqüinos, que propiciaram a coleta separada de fezes e urina, desenvolvidas por STILLIONS e NELSON (1968), ajustadas por FURTADO e TOSI (1996) e com adaptações no coletor de urina e cocho. Foram utilizados cavalos castrados sem raça definida, com idade média de 6 anos.

Em cada ensaio foi avaliado um alimento, objetivando determinar os valores de digestibilidade dos nutrientes. Os procedimentos experimentais foram os mesmos para os quatro ensaios. No primeiro ensaio, avaliou-se a digestibilidade da cana-de-açúcar picada, utilizando-se cinco cavalos com peso médio de $308,3 \pm 9,8 \mathrm{~kg}$. No segundo ensaio, foi testada a combinação de $59 \%$ de cana-de-açúcar picada e $41 \%$ de milho grão inteiro com base na matéria seca, utilizando-se quatro cavalos com peso médio de $331,1 \pm$ $18,0 \mathrm{~kg}$. No terceiro ensaio, os cavalos receberam somente capim-elefante picado, utilizando-se três cavalos com peso médio de $339 \pm 21,7 \mathrm{~kg}$. No quarto ensaio, avaliou-se adição de $6,7 \%$ de uréia à cana-de-açúcar com base na matéria seca ( $1,5 \%$ na matéria natural), com finalidade de atender à exigência de $\mathrm{PB}$ recomendada pelo NRC (1989), utilizando-se três cavalos com peso médio de $319,5 \pm 21,3 \mathrm{~kg}$.

O período pré-experimental teve duração de 20 dias, com objetivo de adaptar os animais à gaiola metabólica e ajustar o consumo de alimento. Durante esse período, os cavalos eram soltos por 2 horas em uma área sem cobertura vegetal para se exercitarem. Nos ensaios em que os cavalos foram alimentados com cana-de-açúcar, foi necessário um período de sete dias anterior ao préexperimento para adaptação a alimentação.

O período experimental teve duração de sete dias, sendo que as coletas de alimento, fezes e urina foram realizadas durante seis dias. Os animais foram pesados ao entrar nas gaiolas, onde permaneceram durante todo o período experimental sem se exercitarem, e ao término do mesmo. O alimento foi fornecido à quantidade determinada no pré-experimento, dividido duas vezes ao dia, às 8 e $16 \mathrm{~h}$, para que houvesse $10 \%$ de sobra. A água foi fornecida à vontade para 
que houvesse sobra, permitindo, assim, medir a ingestão diária.

As coletas de fezes e urina iniciaram-se 24 horas após o fornecimento do alimento teste. As fezes foram coletadas duas vezes ao dia, às 7 e $15 \mathrm{~h}$, retirando-se uma amostra de aproximadamente $200 \mathrm{~g}$ por coleta, por cavalo, para formar uma amostra composta diariamente. A urina foi coletada uma vez ao dia, às $7 \mathrm{~h}$, proveniente de um período de 24 horas, no qual se retirou uma alíquota de $150 \mathrm{~mL}$ por animal, para formar uma amostra composta de $900 \mathrm{~mL}$ no final dos seis dias de coleta. Nos coletores de urina, foram colocados diariamente $60 \mathrm{~mL}$ de $\mathrm{HCl}$ a $50 \%$. Retirouse diariamente uma amostra de alimento em cada arraçoamento, para todos os animais. As sobras foram coletadas integralmente para cada animal e armazenadas separadamente para cada dia. Todo material coletado foi identificado e congelado a $-10^{\circ} \mathrm{C}$, para posterior processamento e análise química.

As análises químicas foram conduzidas no Laboratório de Nutrição Animal do Departamento de Zootecnia da UFLA. Foram analisadas para cada alimento teste: seis amostras de volumoso, referentes a cada dia de coleta (Tabela 1); seis amostras de fezes provenientes de cada dia e de cada cavalo; seis sobras referentes a cada cavalo por dia; uma amostra composta de urina referente aos seis dias de coleta por cavalo; e uma amostra de milho e uma de uréia (Tabela 1). As amostras de alimento, fezes e sobras foram analisadas quanto aos teores de matéria seca (MS), proteína bruta (PB), energia bruta $(\mathrm{EB})$ e fibra em detergente neutro (FDN), de acordo com SILVA (1981). A urina foi analisada quanto aos teores de nitrogênio total e EB, segundo SILVA (1981).

O cálculo da energia metabolizável foi realizado considerando somente as perdas de energia das fezes e da urina, desprezando a perda de energia pelos gases.

Nos valores de digestibilidade dos nutrientes de cada alimento testado, foi realizada análise descritiva para precisar a estimativa por meio do pacote computacional SAEG (Sistema de Análises Estatísticas e Genética), desenvolvido por EUCLYDES (1997).

\section{Resultados e Discussão}

O consumo médio de matéria seca (MS), proteína bruta (PB), energia digestível (ED) e fibra em detergente neutro (FDN) encontram-se na Tabela 2. Comparando-se os consumos médios de MS com valores preconizados pelo NRC (1989) da Tabela 3, observase que os cavalos alimentados com cana-de-açúcar, cana-de-açúcar mais milho e cana-de-açúcar mais

\begin{tabular}{|c|c|c|c|c|}
\hline $\begin{array}{l}\text { Ensaiolalimento } \\
\text { Assay feed }\end{array}$ & $\begin{array}{c}\mathrm{MS}^{1}(\%) \\
D M\end{array}$ & $\begin{array}{c}\mathrm{PB}^{1}(\%) \\
C P\end{array}$ & $\begin{array}{c}\mathrm{EB}^{1}(\mathrm{kcal} / \mathrm{kg}) \\
G E\end{array}$ & $\begin{array}{c}\mathrm{FDN}^{1}(\%) \\
N D F\end{array}$ \\
\hline \multicolumn{5}{|l|}{ Ensaio 1} \\
\hline $\begin{array}{l}\text { Assay } 1 \\
\text { Cana-de-açúcar } \\
\text { Sugar cane }\end{array}$ & 22,41 & 4,82 & 4300 & 61,75 \\
\hline \multicolumn{5}{|l|}{ Ensaio 2} \\
\hline $\begin{array}{l}\text { Assay } 2 \\
\text { Cana-de-açúcar } \\
\text { Sugar cane }\end{array}$ & 24,11 & 4,24 & 4294 & 58,19 \\
\hline $\begin{array}{l}\text { Milho } \\
\text { Corn }\end{array}$ & 88,00 & 9,04 & 4664 & 16,92 \\
\hline \multicolumn{5}{|l|}{ Ensaio 3} \\
\hline $\begin{array}{l}\text { Capim-elefante } \\
\text { Elephante grass }\end{array}$ & 26,66 & 6,04 & 4112 & 77,98 \\
\hline \multicolumn{5}{|l|}{ Ensaio 4} \\
\hline $\begin{array}{l}\text { Assay } 4 \\
\text { Cana-de-açúcar }\end{array}$ & 25,05 & 4,08 & 4463 & 55,40 \\
\hline $\begin{array}{l}\text { Uréia } \\
\text { Urea }\end{array}$ & 98,48 & 46,54 & - & - \\
\hline
\end{tabular}


FIGUEIREDO et al.

Tabela 2 - Consumo médio de matéria seca (MS), proteína bruta (PB), energia digestível (ED) e fibra em detergente neutro (FDN) nos quatro ensaios

Table 2 - Average intake of dry matter (DM), crude protein (CP), digestible energy (DE) and neutral detergent fiber (NDF) in the four assays

\begin{tabular}{|c|c|c|c|c|}
\hline \multirow[t]{2}{*}{$\begin{array}{l}\text { Alimento } \\
\text { Feed }\end{array}$} & \multicolumn{4}{|c|}{$\begin{array}{l}\text { Consumo dos nutrientes } \\
\text { Intake of nutrients }\end{array}$} \\
\hline & $\mathrm{MS}^{1}(D M)$ & $\mathrm{PB}^{1}(C P)$ & $\mathrm{ED}(D E)$ & $\mathrm{FDN}^{1}(N D F)$ \\
\hline Cana-de-açúcar ${ }^{2}$ & $891,8 \pm 144,4$ & $44,8 \pm 6,5$ & $2106 \pm 340$ & $563,8 \pm 86,0$ \\
\hline $\begin{array}{l}\text { Sugar cane } \\
\text { Cana-de-açúcar }+ \text { milho }^{3}\end{array}$ & $1112,5 \pm 97,0$ & $71,4 \pm 5,6$ & $3757 \pm 275$ & $524,7 \pm 47,1$ \\
\hline $\begin{array}{l}\text { Sugar cane }+ \text { corn } \\
\text { Capim-elefante } \\
\text { Elephant grass }\end{array}$ & $2020,0 \pm 144,3$ & $121,8 \pm 8,5$ & $2380 \pm 127$ & $1571,8 \pm 113,5$ \\
\hline $\begin{array}{l}\text { Cana-de-açúcar + uréia }{ }^{4} \\
\text { Sugar cane }+ \text { urea }\end{array}$ & $1031,5 \pm 183,5$ & $282,2^{5} \pm 53,9$ & $2120 \pm 397$ & $533,1 \pm 98,7$ \\
\hline
\end{tabular}

${ }^{1}(\mathrm{~g} / 100 \mathrm{~kg} \mathrm{PV})(\mathrm{g} / 100 \mathrm{~kg} L W)$.

${ }^{2}$ Média de 5 cavalos (Mean of 5 horses).

${ }^{3}$ Média de 4 cavalos (Mean of 4 horses).

${ }^{4}$ Média de 3 cavalos (Mean of 3 horses).

${ }^{5}$ Parte proveniente do NNP da uréia (From of NPN of urea).

Tabela 3 - Consumo médio de MS, PB e ED dos ensaios em comparação aos recomendados pelo NRC (1989) de acordo com PV médio dos cavalos

Table 3 - Average intake of DM, CP and DE of the assays in comparasion to the recomended by NRC (1989), according to the average LW of the horses

\begin{tabular}{|c|c|c|c|c|c|c|}
\hline $\begin{array}{l}\text { Alimento } \\
\text { Feed }\end{array}$ & $\begin{array}{c}\mathrm{MS}^{1} \\
\text { consumida } \\
(\mathrm{kg} / \mathrm{dia}) \\
\text { Intake DM }\end{array}$ & $\begin{array}{c}\mathrm{MS}^{2} \\
\text { exigência } \\
\text { (kg/dia) } \\
\text { Requeriment } D M\end{array}$ & $\begin{array}{c}\mathrm{PB}^{1} \\
\text { consumida } \\
(\mathrm{g} / \text { dia }) \\
\text { Intake } C P^{1}\end{array}$ & $\begin{array}{c}\mathrm{PB}^{2} \\
\text { exigência } \\
\text { (g/dia) } \\
\text { Requeriment } C\end{array}$ & $\begin{array}{c}\mathrm{ED}^{1} \\
\text { consumida } \\
\text { (Mcal/dia) } \\
\text { Intake DE }\end{array}$ & $\begin{array}{c}\text { ED }^{2} \\
\text { exigência } \\
\text { (Mcal/dia) } \\
\text { Requeriment } D E\end{array}$ \\
\hline $\begin{array}{l}\text { Cana-de-açúcar } \\
\text { Sugar cane }\end{array}$ & 2,8 & 5,3 & 139,3 & 426 & 6,5 & 10,6 \\
\hline $\begin{array}{l}\text { Cana-de-açúcar }+ \text { milho } \\
\text { Sugar cane }+ \text { corn }\end{array}$ & 3,6 & 5,7 & 233,7 & 453 & 12,3 & 11,3 \\
\hline $\begin{array}{l}\text { Capim-elefante } \\
\text { Elephant grass }\end{array}$ & 6,9 & 5,8 & 416,0 & 463 & 8,1 & 11,6 \\
\hline $\begin{array}{l}\text { Cana-de-açúcar + uréia } \\
\text { Sugar cane + corn }\end{array}$ & 3,3 & 5,5 & $878,7^{3}$ & 439 & 6,7 & 11,0 \\
\hline
\end{tabular}

Matéria seca (MS), proteína bruta (PB) e energia digestível (ED) (Dry matter [DM], crude protein [CP] and digestible energy [DE]).

1 Consumida no experimento (Intake in the assay).

2 Obtida na tabela de exigência do NRC (1989) (Obtained in the requeriment table of NRC, 1989).

uréia apresentaram consumo menor que a exigência de mantença, exceto para os cavalos alimentados com capim-elefante, em que o consumo foi acima do ideal. O consumo das dietas com base em cana-deaçúcar, provavelmente, foi inibido pela concentração de produtos da digestão no intestino delgado, como a glicose e a produção de ácidos graxos voláteis no ceco (FRAPE, 1992). O aspecto gustativo também poderá influir no consumo, principalmente para os cavalos alimentados com cana-de-açúcar combinada com uréia. Apesar do curto período de coleta de dados, verificou-se perda de peso, de 5,2; 5,7; e $7,7 \mathrm{~kg}$, respectivamente, dos cavalos alimentados com canade-açúcar, cana-de-açúcar mais milho e cana-deaçúcar mais uréia. MACHADO (1992), em expe- rimentos de metabolismo nos quais a cana-de-açúcar participou em $45 \%$ da ração, obteve consumo de MS de $2,31 \%$ da peso corporal dos cavalos, valor este acima do encontrado nos ensaios com cana-de-açúcar $(0,89 \%)$, cana-de-açúcar mais milho (1,11\%) e cana-de-açúcar mais uréia $(1,03 \%)$. No experimento realizado por FURTADO (1991), utilizando capim-elefante com concentrado adicionado ou não de uréia, não foi observada redução do consumo de MS para os tratamentos com 1 e $2 \%$ de uréia em relação à ração sem uréia.

Na Tabela 3, pode-se fazer avaliação do consumo de $\mathrm{PB}$ e ED em relação às exigências dos animais. Para todos os alimentos testados, exceto para canade-açúcar mais uréia, o consumo de PB foi inferior à exigência, enquanto para o consumo de ED, somente 
para a cana-de-açúcar mais milho, constatou-se consumo superior ao da exigência dos animais. Parte da PB consumida no ensaio de cana-de-açúcar mais uréia foi proveniente do nitrogênio não-protéico (NNP) da uréia, embora não tenha sido possível determinar a quantidade exata, porque o consumo foi à vontade (com sobras).

A relação do consumo de água e matéria seca dos alimentos foi de 1,7; 1,7; 1,6; e 2,3 litros de água/kg de MS consumida, para os ensaios 1, 2, 3 e 4, respectivamente. Estes resultados se aproximam dos 2 litros de água/kg de MS consumida para cavalos adultos em ambiente uniforme (FRAPE, 1992). Leitch e Thomson, citados pelo NRC (1989), concluíram que cavalos necessitam de 2 a 3 litros de água/kg de MS consumida.

Os coeficientes de digestibilidade aparente de MS, PB, EB e FDN encontram-se na Tabela 4 com suas respectivas estimativas de precisão. Os valores de digestibilidade aparente da MS, PB e EB da canade-açúcar foram similares aos citados por ARAÚJO et al. (1996), que obtiveram valores médios de digestibilidade aparente da MS, PB e EB de 57,46; 55,06 ; e 54,37\%, respectivamente, utilizando o método do saco de náilon móvel. O resultado de digestibilidade aparente do FDN foi superior em $28 \%$ aos obtidos por ARAÚJO et al. (1996).

A digestibilidade do milho acima de $90 \%$, segundo ARAÚJO et al. (1996), provavelmente foi o principal fator que contribuiu para que a combinação de milho e cana-de-açúcar resultasse em altos coeficientes de digestibilidade aparente da MS, PB, EB e FDN.

Resultados deste trabalho mostram que a utilização de cana-de-açúcar, apesar de seu baixo teor protéico, é um volumoso com potencial na alimenta- ção de cavalos adultos. Os altos coeficientes de digestibilidade da MS, PB, EB e FDN, apresentados pela cana-de-açúcar, podem ser resultantes de maior escape de carboidratos solúveis para o intestino grosso, melhorando assim o processo fermentativo e estimulando maior digestão e síntese protéica. O tempo de permanência da cana-de-açúcar no intestino grosso dos cavalos também pode ter favorecido a digestibilidade da mesma, como citado por MACHADO (1992).

A adição de uréia à cana-de-açúcar com objetivo de aumentar o valor nutricional, como alternativa de volumoso para suplementação nos períodos de baixa disponibilidade de forragem, não se mostrou eficiente. Esta combinação, apesar de propiciar elevada digestibilidade aparente da $\mathrm{PB}$, proporcionou retenção de nitrogênio negativa (-73,4 g/dia) nos cavalos. Isto sugere que a uréia é absorvida no intestino delgado e grandemente eliminada via urina, e assim não alcança o intestino grosso para ser incorporado na proteína microbiana e utilizada pelo cavalo. Estes resultados corroboram os encontrados por REITNOUR e TREECE (1971) e MARTIN et al. (1996), os quais verificaram retenção de nitrogênio negativo em cavalos adultos, alimentados com dietas contendo baixo teor protéico suplementadas com uréia.

Os valores de digestibilidade da MS e PB do capim-elefante diferiram dos valores encontrado por ARAÚJO et al. (1996) e FURTADO (1992), enquanto os valores de digestibilidade da EB e FDN foram bastante similares aos citados por ARAÚJO et al. (1996), que obtiveram valores de digestibilidade da MS e da FDN de 30,08 e 27,74\%, respectivamente.

Os resultados de proteína digestível (PD), ener-

Tabela 4 - Coeficientes médios de digestibilidade aparente de MS, PB, EB e FDN

Table 4 - Average coefficients of apparent digestibility DM, CP, GE and NDF

\begin{tabular}{|c|c|c|c|c|}
\hline \multirow[t]{3}{*}{$\begin{array}{l}\text { Alimento } \\
\text { Feed }\end{array}$} & \multicolumn{4}{|c|}{$\begin{array}{l}\text { Coeficientes de digestibilidade aparente } \\
\text { Coefficients of apparent digestibility }\end{array}$} \\
\hline & MS (\%) & $\mathrm{PB}(\%)$ & $\mathrm{EB}(\%)$ & FDN (\%) \\
\hline & $D M$ & $C P$ & $G E$ & $N D F$ \\
\hline $\begin{array}{l}\text { Cana-de-açúcar } \\
\text { Sugar cane }\end{array}$ & $55,3 \pm 1,5$ & $52,3 \pm 1,9$ & $54,7 \pm 1,4$ & $44,5 \pm 1,8$ \\
\hline $\begin{array}{l}\text { Cana-de-açúcar }+ \text { milho }^{2} \\
\text { Sugar cane }+ \text { corn }^{2}\end{array}$ & $74,7 \pm 1,4$ & $71,5 \pm 1,5$ & $75,3 \pm 1,31$ & $58,1 \pm 2,6$ \\
\hline $\begin{array}{l}\text { Capim-elefante } \\
\text { Elephant grass }\end{array}$ & $29,9 \pm 0,9$ & $44,9 \pm 0,8$ & $28,8 \pm 1,0$ & $28,3 \pm 1,1$ \\
\hline $\begin{array}{l}\text { Cana-de-açúcar }+ \text { uréia }^{3} \\
\text { Sugar cane }+ \text { urea }^{3}\end{array}$ & $55,4 \pm 1,2$ & $92,0 \pm 1,6$ & $50,5 \pm 0,41$ & $32,6 \pm 2,0$ \\
\hline
\end{tabular}


gia digestível (ED) e energia metabolizável (EM) estão apresentados na Tabela 5. GARCIA (1995), utilizando valores de digestibilidade da MS obtidos in vitro, encontrou valores de ED para capim-elefante e cana-de-açúcar, respectivamente, de $1930 \mathrm{kcal} / \mathrm{kg}$ de MS e $2500 \mathrm{Mcal} / \mathrm{kg}$ de MS, superiores em 38,7 e $5,6 \%$, respectivamente, aos encontrados nestes ensaios. Estas diferenças, possivelmente, são resultados da metodologia usada e da variação na composição química dos alimentos testados.

No cálculo da EM nestes ensaios, foram desprezadas as perdas de energia por gases. Segundo PAGAN e HINTZ (1986), as perdas de energia por metano estão em torno de $2,9 \pm 0,1 \%$ da energia bruta e 4,6 $40,1 \%$ da ED. Portanto, as EM estimadas nestes ensaios podem ser consideradas superestimadas, porém são mais precisas que a ED. As perdas de energia bruta na urina foram de 12,$0 ; 6,3 ; 9,7 ;$ e $16,9 \%$ para a cana-de-açúcar, cana-de-açúcar mais milho, capim-elefante e cana-de-açúcar mais uréia, respectivamente. PAGAN e HINTZ (1986) encontraram perda média de energia bruta na urina de $8,5 \pm 0,32 \%$. A utilização de EM na formulação de dietas para eqüinos, deverá ser mais eficiente, pois as perdas de energia bruta na urina e por intermédio do metano estão entre 10 e $15 \%$.

Tabela 5 - Valores de proteína digestível (PD), energia digestível (ED) e energia metabolizável (EM) Table 5 - Values of crude protein (CP), digestible energy (DE) and metabolizable energy (ME)

\begin{tabular}{|c|c|c|c|}
\hline Alimento & $\mathrm{PD}(\%)$ & $\mathrm{ED}(\mathrm{kcal} / \mathrm{kg})$ & $\mathrm{EM}^{4}(\mathrm{kcal} / \mathrm{kg})$ \\
\hline Feed & $C P$ & $D E$ & $M E^{4}$ \\
\hline Cana-de-açúcar $^{1}$ & $2,65 \pm 0,07$ & $2361 \pm 61$ & $2078 \pm 66$ \\
\hline $\begin{array}{l}\text { Sugar cane } \\
\text { Cana-de-açúcar }+ \text { milho }^{2} \\
\text { Sugar cane }+ \text { corn }^{2}\end{array}$ & $4,59 \pm 0,13$ & $3382 \pm 59$ & $3167 \pm 80$ \\
\hline $\begin{array}{l}\text { Capim-elefante }{ }^{3} \\
\text { Elephant grass }\end{array}$ & $2,71 \pm 0,05$ & $1182 \pm 40$ & $1067 \pm 50$ \\
\hline $\begin{array}{l}\text { Cana-de-açúcar }+ \text { uréia }^{3} \\
\text { Sugar cane }+ \text { urea }^{3}\end{array}$ & $26,06 \pm 5,95$ & $2060 \pm 53$ & $1711 \pm 56$ \\
\hline
\end{tabular}

\section{Conclusões}

Os valores de energia digestível para a cana-deaçúcar, cana-de-açúcar mais milho, cana-de-açúcar mais uréia e capim-elefante foram 2361, 3382, 2060 e $1182 \mathrm{kcal} / \mathrm{kg}$ de matéria seca, respectivamente.

\section{Referências Bibliográficas}

ARAÚJO, K.V., LIMA, J.A., TEIXEIRA, J.C. et al. 1996. Determinação da digestibilidade aparente dos nutrientes de alguns concentrados e volumosos para eqüinos, pela técnica do saco de náilon móvel. R. Soc. Bras. Zootec., 25(5):944-956.

EUCLYDES, R.F. 1997. Manual de utilização do Programa SAEG (Sistema para Análises Estatísticas e Genética) UFV, Viçosa. 150p.(versão7.0).

FRAPE, D. 1992. Nutrición y alimentación del caballo. Ed Acribia: Zaragoza. 404p.

FURTADO, C. E., TOSI, H. Gaiola de metabolismo para eqüinos. In: REUNIÃO ANUAL DA SOCIEDADE BRASILEIRA DE ZOOTECNIA, 33, Fortaleza, 1996. Anais.... Fortaleza: SBZ. 1996. p.192-193.

FURTADO, S. I. Experimento de digestibilidade em eqüinos recebendo rações com uréia. Viçosa: UFV, 1992. 59p. Dissertação (Mestrado em Zootecnia) - Universidade Federal de Viçosa, 1992.

GARCIA, J. A. S. Substituição parcial do capim elefante (Pennisetum purpureum, Schum.) pela cana-de-açúcar (Sccharum officinarum, L.) na alimentação de eqüinos em fase de crescimento. Viçosa, UFV, 1995. 54p. Dissertação (Mestrado em Zootecnia) - Universidade Federal de Viçosa, 1995.

HINTZ, H.F., SCHRYVER, H.F. 1972. Nitrogen utilization in ponies. J. Anim. Sci., 34(4):592-595, 1972.

MACHADO, H. de M. Efeito de diferentes combinações de capim elefante (Pennisetum purpureum, Schum.): cana-de-açúcar (Sccharum officinarum, L.) sobre a digestibilidade, em eqüinos, utilizando diferente metodologias de determinação. Viçosa, UFV, 1992, 71p. Dissertação (Mestrado em Zootecnia) Universidade Federal de Viçosa, 1992.

MANZANO, A., NOVAES, N.J., HADDAD, C.M. et al. 1979. Feno de capim-de-rhodes (Chloris gayana, Kunth) e capim elefante (Pennisetum purpureum, Schum) var. napier verde picado na alimentação de equídeos em crescimento. $R$. Soc. Bras. Zootec., 8(4):642-653.

MANZANO, A., NOVAES, N.J., HADDAD, C.M. et al. 1980. Comparação entre coeficiente de digestibilidade de rações com feno de capim de rhodes e capim elefante var. napier verde picado, em equídeos. R. Soc. Bras. Zootec., 9(4):673-690.

MARTIN, R. G., McMENIMAN, N. P., NORTON, B. W. et al. 
772 Rev. bras. zootec.

1996. Utilization of endogenous and dietary urea in the large intestine of the mature horse. Br. J. Nut., 76:373-386.

NATIONAL ACADEMY PRESS. 1989. Nutrient requeriments of horses. 5. ed. Rev. Washinton D.C. 100p.

PAGAN, J.D., HINTZ, H.F. 1986. Equine energetics. I. Relationship betweem body weight and energy requirements in horses. J. Anim. Sci.., 63:815-821.

REITNOUR, C.M., TREECE, J.M. 1971. Relationship of nitrogen source to certain blood components and nitrogen balance in the equine. J. Anim. Sci., 32(3):487-490.

SILVA, D.J. 1990. Análise de Alimentos (métodos químicos e biológicos). Viçosa, UFV. 166p.
SLADE, L.M., ROBINSON, D.W., CASEY, K.E. 1970. Nitrogen metabolism in nonruminant herbivores. I The influence of nonprotein nitrogen and protein quality on the nitrogen retention of adult mares. J. Anim. Sci., 30:753-760.

STILLIONS, M.C., NELSON, N.E. 1968. Metabolism stall for male equine. J. Anim. Sci., 27(1):68-72.

Recebido em: 18/05/98

Aceito em: 26/01/99 